\title{
O papel das mídias e o modelo de curso na educação a distância
}

\author{
Rafaela Lunardi Comarella, UFSC/(PGEGC), rafaela@egc.ufsc.br \\ Júlio César da Costa Ribas, UFSC/(PGEGC)/IF-SC, julio@ifsc.edu.br \\ Araci Hack Catapan, UFSC/(PGEGC), aracihack@gmail.com
}

Resumo: A evolução das tecnologias de informação e comunicação e o crescimento substancial da educação a distância, aliados ao surgimento das novas mídias, promovem mudanças profundas no panorama do ensino-aprendizagem. Uma grande variedade de mídias são utilizadas na estruturação de um modelo de curso. A escolha adequada de mídias assim como a adequada estruturação dos cursos são fundamentais para a consolidação do sistema de educação a distância. O presente artigo versa sobre os conceitos relacionados à escolha da mídia e ao modelo de curso na modalidade a distância, partindo do estudo dos modelos de comunicação no contexto educacional. Ilustra a referida abordagem com um estudo de caso.

Palavras-chave: educação a distância, mídias, modelos de curso, modelos de comunicação

\section{The role of media and the course model in distance education}

Abstract: The evolution of the technologies of information and communication and the substantial growth of distance education, associated with the emergence of new media, promotes deep changes in the scenery of teaching-learning. A wide variety of media is used in the structuring of a course model. The appropriate choice of media as well as the appropriated structuring of the courses are fundamental for the consolidation of the system of distance education. This article discusses concepts related to the choice of media and the model of course in distance education, by studying the patterns of communication in the educational context. This approach is illustrated with a case study.

Keywords: distance education, media, course models, communication models

\section{INTRODUÇÃO}

O desenvolvimento de projetos educacionais a distância com qualidade técnicopedagógica requer minuciosos cuidados em suas diversas nuances. $\mathrm{O}$ modelo do curso e a escolha de mídias adequadas às condições e população alvo são os primeiros aspectos a serem considerados. Segundo Kenski (2005, p. 2),

Em geral, quando nos referimos ao uso de mídias em projetos educacionais, a nossa imaginação nos articula diretamente às mais novas oportunidades tecnológicas de informação e comunicação, ou seja, a internet e todos os seus desdobramentos e inovações. Pensamos também no uso de programas televisivos, filmes e vídeos. Outros meios - como o rádio, o jornal e todas as formas midiáticas impressas etc. - ainda que conhecidos e utilizados em atividades de ensino, não são tão fortemente destacados nas pesquisas e publicações da área educacional. São muitas as mídias utilizadas em atividades educativas. Assim como cada modalidade de ensino requer o tratamento diferenciado do mesmo conteúdo - de acordo com os alunos, os objetivos a serem alcançados, o espaço e tempo disponível para a sua 
realização - cada um dos suportes midiáticos tem cuidados e formas de tratamento específicas que, ao serem utilizados, alteram a maneira como se dá e como se faz a educação.

A evolução das tecnologias de informação e comunicação e o crescimento vertiginoso da educação a distância, seja no cenário mundial ou nacional, aliados ao surgimento das novas mídias, promovem mudanças profundas no panorama do ensino-aprendizagem. A escolha adequada da tecnologia e de mídias assim como o planejamento dos cursos passaram a ser fundamentais para a consolidação do sistema de educação a distância. Neste estudo, abordam-se alguns conceitos, tendo por objetivo orientar a escolha da mídia e do modelo de curso na modalidade a distância, tomando como referência os modelos de comunicação no contexto educacional. Apresenta-se um estudo de caso para exemplificar a sua utilização.

\section{MODELOS DE COMUNICAÇÃO E AS MÍDIAS}

Segundo Catapan (2010, p. 75), “a multiplicidade de condições de comunicação possibilita compartilhar as atividades com todos os envolvidos no processo, em tempos e espaços diversos e contínuos”. Não há educação sem comunicação e não faz sentido ocorrer a comunicação sem a existência dos atos da educação. Estes dois conceitos estão íntima e fortemente conectados, já que nenhum deles ocorre de forma isolada.

Para Thayer (1979), a comunicação "é o processo vital através do qual indivíduos e organizações se relacionam uns com os outros, influenciando-se mutuamente”. Educação, segundo Puig (1986), “designa e engloba todos aqueles fatores humanos nos quais se dá um processo de criação ou transmissão de informação e cujo protagonista é o homem que assimila tal informação". Temos ao nosso dispor um grande número sistemas de comunicação e uma não menor variedade de estudos buscando explicar de que forma o fenômeno da comunicação ocorre entre as pessoas, máquinas ou entre pessoa e máquina.

Diversos estudos têm procurado explicar de que forma o processo da comunicação tem ocorrido e assim surgem diferentes correntes de pensamentos e, consequentemente, distintos modelos. Podemos agrupar os modelos mais amplamente propalados em quatro categorias ou correntes de pesquisa: modelo de base linear, modelo de base cibernética, modelo de comunicação de massas e modelos culturais.

Conforme Freixo (2006), os estudos relativos à comunicação sofreram de forma significativa a influência do cientista social norte-americano Harold Lasswell, em 1948, e, quase que simultaneamente, em 1949, de Shannon e Weaver. Ambos os trabalhos apresentados se enquadram no modelo de base linear, que têm a particularidade de dissociar as funções do emissor e do receptor, apresentando a comunicação como uma transmissão unidirecional de mensagens.

Recorremos ao modelo tradicional de comunicação de Shannon e Weaver para entendermos os elementos básicos do processo de comunicação, sem nos preocuparmos com a forma de transmissão da mensagem. A figura 1 apresenta o modelo e seus principais elementos. 


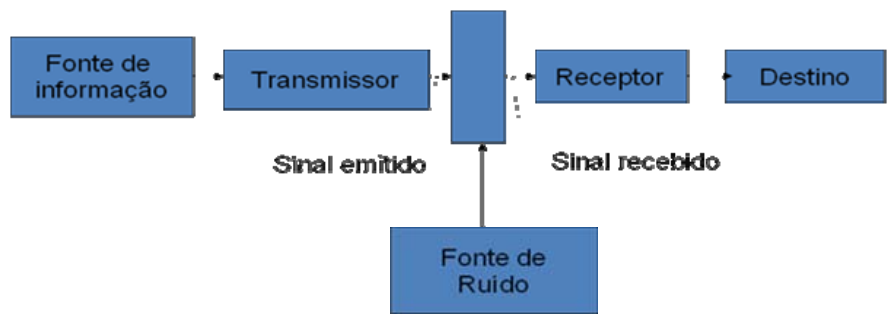

Figura 1: Modelo de Shannon e Weaver

Shannon e Weaver, em 1949, publicaram uma teoria de comunicação denominada “Teoria Matemática da Comunicação", que tem como objetivo medir a quantidade de informação contida numa mensagem e a capacidade de informação de um dado canal. A fonte é tida como detentora do poder de decisão, isto é, decide qual a mensagem a enviar, selecionando uma dentre um conjunto de mensagens possíveis; esta mensagem selecionada é depois transformada pelo transmissor num sinal, que é enviado ao receptor através do canal. Outro termo que aparece neste modelo é o ruído. O ruído é algo que é acrescentado ao sinal, entre a sua transmissão e a sua recepção e que não é pretendido pela fonte.

Diferentemente do modelo de base linear, os modelos cibernéticos consideram a retroação ou feedback como um elemento regulador da circularidade da informação. Os modelos de comunicação de massa foram incluídos nos modelos de base cibernética pelo fato de os meios de comunicação de massa se basearem nos princípios de retroação ou feedback. Neste caso, o emissor ou o transmissor de informação é coletivo.

A outra corrente de pesquisa em comunicação, a do modelo cultural, estuda a cultura de massa e as suas repercussões na sociedade. A preocupação centra-se nestes aspectos e não nos meios de comunicação.

Almeida (2003) destaca modalidades de comunicação conforme o tipo de mídia disponível: A comunicação de uma para outra pessoa pode ser exemplificada pela comunicação via telefone, webmail e outras ferramentas de transmissão de vídeo e voz pela Internet. A comunicação de um para muitos ocorre, por exemplo, com o uso de fóruns e listas de discussão na web.

Para Almeida (2003), a comunicação de muitas para muitas pessoas ocorre no grupo virtual, como é o caso de comunidades colaborativas em que todos participam da criação e desenvolvimento da comunidade. Ferramentas como a tele e a videoconferência permitem que ocorra comunicação entre várias pessoas, simultaneamente e em regiões geográficas distintas.

As mídias, portanto, desempenham um papel fundamental no processo de comunicação e, proporcionalmente à sua importância, devem ser cuidadosamente analisadas e selecionadas, já que seu uso inadequado seguramente é um dos fatores que acarretam desmotivação, baixa qualidade dos cursos e alto índice de evasão.

Moore e Kearsley (2007) destacam que se devem analisar as características das mídias no processo de sua seleção. Esses autores explicam que há aspectos positivos e negativos em cada um dos tipos de mídias. O material impresso tem a vantagem de ser relativamente barato para desenvolver e distribuir, além de ser confiável. Comporta amplos volumes de informação de forma eficiente, e o estudante pode ler o material em qualquer lugar. Contudo, para os autores, é difícil escrever o texto de forma que estimule os educandos a se manter envolvidos, sendo que a mídia impressa é um material passivo.

Por outro lado, cursos baseados no computador proporcionam um grande volume de informações, além de poderem dispor de áudio e vídeo, o que é atrativo para estudantes que acham o material impresso desmotivador. No entanto, esse tipo de 
material pode requerer alguns requisitos tecnológicos para o estudante além de, em geral, ser mais caro e consumir mais tempo para a produção. Segundo Moore e Kearsley (2007) "existem numerosos modelos consolidados para orientar o processo de seleção de mídias e tecnologia." São os seguintes os principais passos em todos os modelos:

1. Identificar os atributos da mídia exigidos pelos objetos de instrução ou pelas atividades de aprendizado;

2. Identificar as características dos alunos que sugerem ou eliminam certas mídias;

3. Identificar características do ambiente de aprendizagem que oferecem ou eliminam certas mídias;

4. Identificar os fatores econômicos ou organizacionais que podem afetar a viabilidade de certas mídias.

Adicionalmente, Moore e Kearsley (2007) elencam princípios gerais que devem ser observados em relação à adoção das tecnologias e mídias utilizadas na educação a distância, na criação de cursos:

- Boa estruturação dos cursos: A organização do curso e seus componentes devem estar claramente definidos e compreensíveis aos alunos;

- Objetivos claros: Inclui-se aqui a seleção adequada de tecnologia e mídias, assim como instrumentos apropriados de avaliação;

- O conteúdo do curso deve ser desmembrado em unidades menores;

- Participação planejada dos alunos;

- Integralidade no que diz respeito aos materiais do curso: Devem transcender a sua função, como por exemplo o material didático devendo conter comentários, ilustrações, entre outros;

- A repetição como elemento de reforço e compensação de distrações;

- A síntese deve ser utilizada e estimulada através de resumos, interligando idéias;

- Simulação e variedade devem estar presentes nos mais diversos formatos e tipos de mídias, objetivando atender os variados interesses dos alunos;

- A modularidade deve ser contemplada nos exercícios, exemplos e problemas, para que os alunos tenham a possibilidade de adaptar o conteúdo aos interesses;

- Feedback e avaliação devem ser elementos constantes no progresso do curso. A eficácia da mídia deve ser monitorada e avaliada no dia-a-dia do curso.

Por fim, um modelo adequado de curso e a escolha de mídias devem estar permanentemente presentes no processo comunicativo educacional. Observar criteriosamente estes elementos é priorizar a qualidade através do uso adequado das tecnologias de informação e comunicação e do planejamento como elemento norteador.

\section{UM OLHAR PARA OS MODELOS DE CURSO NA EDUCAÇÃO A DISTÂNCIA}

Uma das principais definições para realizar um curso na modalidade a distância é a escolha do modelo de curso. E esta, por sua vez, está vinculada à escolha das mídias utilizadas, tais como material impresso, videoconferência, Ambiente Virtual de EnsinoAprendizagem (AVEA), vídeos, entre outros.

O modelo de curso adotado por uma instituição deve estar pautado na organização de estratégias de disponibilização de conteúdo e de interação entre estudantes, professores e tutores, de forma a promover o processo de ensino- 
-aprendizagem com seus estudantes. Para que isso ocorra, é necessário pensar em questões como seleção de material, mídias a serem utilizadas, estratégias pedagógicas, métodos de avaliação, já que essas questões são inerentes ao modelo de curso adotado (Moore e Kearsley, 2007; Comarella, 2009). Rodrigues (2004, p.70) afirma:

Os modelos de cursos são derivados dos requisitos de ensino-aprendizagem das diversas áreas do conhecimento e se apresentam como um componente fundamental da $\mathrm{EaD}$, pois é com base no desenho instrucional do curso que os estudantes têm acesso aos materiais e realizam suas atividades.

Com a evolução das tecnologias de informação e comunicação, durante a década de 90, também ocorreu um desenvolvimento na área de acesso aos materiais dos cursos, e a comunicação em tempo real (síncrona) e assíncrona tornaram-se mais fáceis. Novos sistemas de conferência foram disponibilizados, com interfaces mais intuitivas, facilitando a utilização pelos estudantes, potencializando a aprendizagem on-line (Keegan, 2008).

Peters (2002) diz que, frequentemente, os conceitos relacionados à $\mathrm{EaD}$ tornam-se tão sólidos que são transformados em modelos, testados e colocados em prática. Desta forma, apresenta, baseado em seus fundamentos conceituais, os modelos descritos no quadro 1.

Quadro 1: Categorias de Modelos de Cursos

\begin{tabular}{|l|l|}
\hline $\begin{array}{l}\text { Modelo de educação por } \\
\text { correspondência }\end{array}$ & $\begin{array}{l}\text { O estudante recebe o material impresso para estudar e posteriormente } \\
\text { realizar os exames, o apoio de tutoria pode ou não ser oferecido. "O } \\
\text { modelo de educação por correspondência ainda é usado amplamente, } \\
\text { apesar do interesse mundial na informatização da EaD". }\end{array}$ \\
\hline $\begin{array}{l}\text { Modelo multimídia } \\
\text { (de massa) }\end{array}$ & $\begin{array}{l}\text { A integração das mídias rádio, televisão e material impresso, de forma } \\
\text { planejada e estruturada, para promover ensino-aprendizagem. }\end{array}$ \\
\hline Modelo de EaD em grupo & $\begin{array}{l}\text { Neste modelo há a integração das mídias: rádio e televisão, sendo } \\
\text { que as transmissões das aulas acontecem para determinados grupos } \\
\text { de estudantes que freqüentam classes obrigatórias, um instrutor faz a } \\
\text { explanação do conteúdo e proporciona momentos de discussão entre } \\
\text { os estudantes. Outra característica é que geralmente não é oferecido } \\
\text { material impresso, apenas notas de aula. }\end{array}$ \\
\hline Modelo baseado em rede & $\begin{array}{l}\text { Integra múltiplas mídias, linguagens e recursos, apresentando as } \\
\text { informações de maneira organizada, através de um ambiente } \\
\text { informatizado. Possibilita também a realização de interações entre os } \\
\text { estudantes, tutores e professores de forma virtual. É um modelo } \\
\text { complexo e que vem ganhando espaço devido a evolução da } \\
\text { informática. }\end{array}$ \\
\hline $\begin{array}{l}\text { Modelo sala de aula } \\
\text { estendido } \\
\text { tecnologicamente }\end{array}$ & $\begin{array}{l}\text { Neste modelo as aulas acontecem em uma sala ou estúdio, e são } \\
\text { transmitidas para duas ou mais salas através de cabo, satélite ou } \\
\text { sistema de videoconferência. }\end{array}$ \\
\hline
\end{tabular}

Fonte: Adaptado por COMARELLA (2009) de Petters (2000).

Pelo quadro 1, percebe-se que uma das características que distinguem os modelos de curso define-se pela mídia que é utilizada, ou seja, a forma pela qual o estudante tem o acesso ao conteúdo do curso. Petters (2002) utilizou como parâmetros 
classificatórios a finalidade do curso e o número de estudantes que se pretende atingir. É importante ter clareza que, independentemente das mídias utilizadas, o sistema de EaD de uma instituição deve ser planejado tendo em vista o tipo de recurso de infraestrutura que o estudante terá para acessar o curso (Rumble, 2003). Não tem sentido, por exemplo, montar um curso baseado em videoconferências para ser oferecido em um lugar aonde o sinal do satélite não chega.

No Brasil, segundo Sanchez (2007) o material impresso (livros, apostilas) é a mídia mais utilizada pelas instituições de $\mathrm{EaD}$, chegando a 86,4\% delas (Tabela 1). Mais da metade (56\%) utiliza o modelo de EaD baseado em rede (e-learning ).

Tabela 1: Mídias utilizadas, por região geográfica no Brasil

\begin{tabular}{|c|c|c|c|c|c|c|c|c|c|c|c|c|}
\hline \multirow{2}{*}{ Mídias Utilizadas } & \multicolumn{2}{|c|}{ Centro-Oeste } & \multicolumn{2}{|c|}{ Norte } & \multicolumn{2}{|c|}{ Nordeste } & \multicolumn{2}{|c|}{ Sul } & \multicolumn{2}{|c|}{ Sudeste } & \multicolumn{2}{|c|}{ Total } \\
\hline & Freq. & $\%$ & Freq. & $\%$ & Freq. & $\%$ & Freq. & $\%$ & Freq. & $\%$ & Freq. & $\%$ \\
\hline Material impresso & 13 & 81,3 & 7 & 87,5 & 12 & 92,3 & 33 & 86,8 & 43 & 86,0 & 108 & 86,4 \\
\hline E-leaming & 9 & 56,3 & 2 & 25,0 & 9 & 69,2 & 19 & 50,0 & 31 & 62,0 & 70 & 56,0 \\
\hline Televisão & 3 & 18,8 & 4 & 50,0 & 8 & 61,5 & 12 & 31,6 & 9 & 18,0 & 36 & 28,8 \\
\hline Vídeo & 6 & 37,5 & 4 & 50,0 & 5 & 38,5 & 16 & 42,1 & 18 & 36,0 & 49 & 39,2 \\
\hline $\mathrm{CD}$ & 11 & 68,8 & 2 & 25,0 & 4 & 30,8 & 17 & 44,7 & 27 & 54,0 & 61 & 48,8 \\
\hline DVD & 5 & 31,3 & 2 & 25,0 & 6 & 46,2 & 18 & 47,4 & 18 & 36,0 & 49 & 39,2 \\
\hline Rádio & 1 & 6,3 & 0 & 00 & 2 & 15,4 & 5 & 13,2 & 6 & 12,0 & 14 & 11,2 \\
\hline Videoconferência & 0 & 0,0 & 0 & 0,0 & 2 & 15,4 & 12 & 31,6 & 12 & 24,0 & 26 & 20,8 \\
\hline Outras & 3 & 18,8 & 1 & 12,5 & 3 & 23,1 & 8 & 21,1 & 8 & 16,0 & 23 & 18,4 \\
\hline NR/NA & 1 & 6,3 & 0 & 0,0 & 0 & 0,0 & 1 & 2,6 & 3 & 6,0 & 5 & 4,0 \\
\hline Total de Instituições & 16 & & 8 & & 13 & & 38 & & 50 & & 125 & \\
\hline
\end{tabular}

Fonte: Sanchez (2007)

Conforme o material utilizado e a abordagem instrucional, existe uma necessidade maior ou menor de interação entre os estudantes, tutores e professores, de forma que todas as interações, síncronas ou assíncronas, têm implicações importantes para o processo de ensino-aprendizagem. O mais importante é que a escolha do modelo do curso seja feita de forma a atender às necessidades do público alvo, dentro das possibilidades da instituição, assegurando a entrega do material, o aprendizado do estudante e a qualidade de ensino.

\section{UM ESTUDO DE CASO: o curso superior de tecnologia ofertado pelo Instituto Federal de Santa Catarina (IF-SC)}

Baseado nos fundamentos conceituais abordados no presente artigo, o Curso Superior de Tecnologia em Gestão Pública ofertado pelo Instituto Federal de Santa Catarina foi concebido com a utilização do modelo de comunicação de base cibernética e do modelo de curso baseado em rede. O acesso ao referido curso é oportunizado pelo vestibular, que oferta 50 vagas por polo. Um dos critérios de seleção é a comprovação de conclusão do ensino médio. Ao aluno concluinte é garantido um diploma, equivalente ao dos cursos de graduação presenciais, emitido pelo IF-SC.

A Sede possui uma infra-estrutura gerida basicamente por quatro coordenações: coordenação UAB, coordenação do curso, coordenação de produção de materiais e coordenação de tutoria. É na Sede que ocorrem diversas atividades, tais como: seleção de professores e tutores; planejamento, produção e disponibilização dos materiais necessários para oferta das unidades curriculares (UCs); criação e atualização de normas, regimentos, calendários e manuais; condução dos trâmites de secretaria acadêmica. 
No Polo há uma infraestrutura que comporta atividades acadêmicas de 50 alunos, orientados por dois tutores presenciais (tp) (1 para cada 25 alunos), todos sob o cuidado atento do coordenador de polo, como mostra a figura 2.

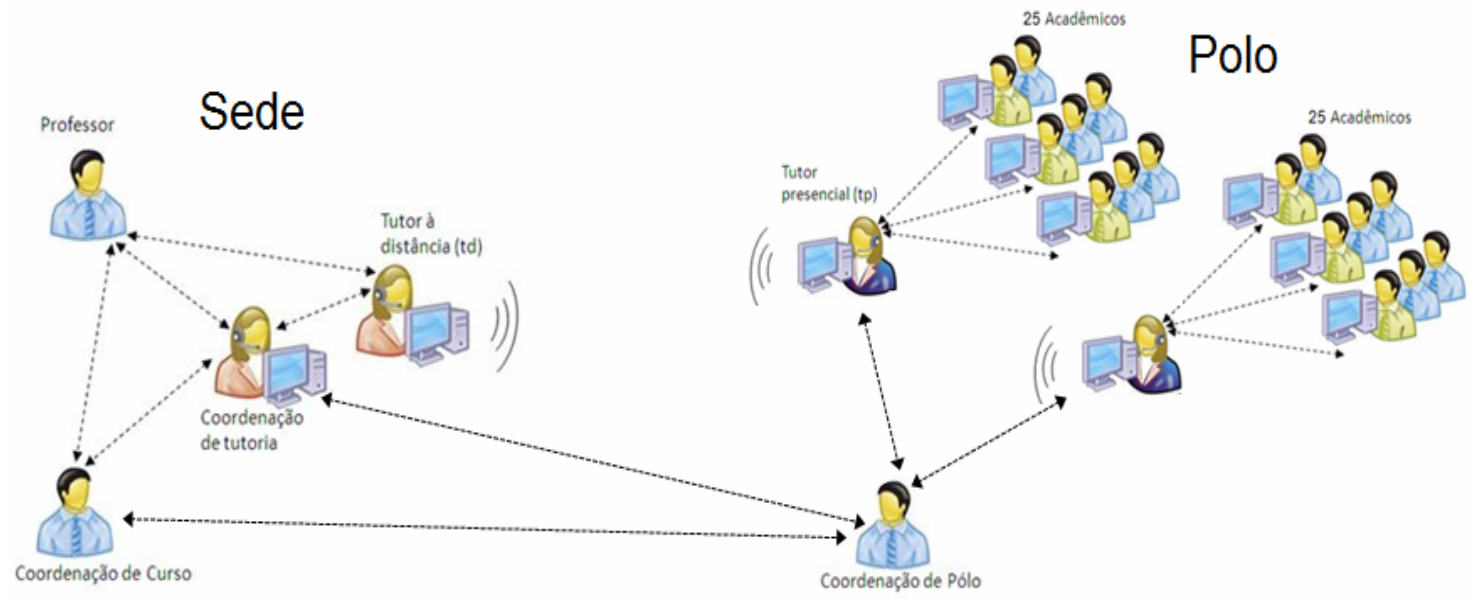

Figura 2: Dinâmica de relacionamentos do curso ofertado pelo IF-SC.

Na Sede, existem dois tutores a distância (td) para cada pólo, e a equipe de tutoria é liderada por uma coordenação de tutoria. No Curso Superior de Tecnologia em Gestão Pública, tanto os tutores presenciais quanto os a distância têm o papel de mediadores entre professores e alunos. É o tutor que normalmente orienta os alunos em suas dúvidas e os motiva a superá-las, auxilia-os no uso dos materiais, dos ambientes virtuais, esclarece o funcionamento do curso e as regras do sistema de avaliação. Os tutores a distância contam com um plano instrucional (PI) elaborado pelo professor durante a etapa de planejamento da unidade curricular (UC). Nele consta o planejamento das atividades que serão desenvolvidas pelo docente, ou seja, o conteúdo das aulas, a divisão de equipes, a quantidade de tarefas, exercícios, provas, datas e regras de avaliações.

O professor mantém contato direto com os alunos pelo sistema de videoconferência, pelos fóruns do ambiente virtual de ensino-aprendizagem e nos encontros presenciais nos polos. Os encontros presenciais que acontecem em um dos polos são transmitidos para os demais, potencializando essa ação. Tal momento é muito elogiado pelos alunos, que podem interagir presencialmente com o docente, e é enriquecedor para o professor que visita o polo e compreende a realidade de funcionamento do mesmo.

Para que haja comunicação eficiente, distintas mídias são utilizadas no processo de interação entre os atores que estão na sede e nos polos. As mais utilizadas são:

- As aulas realizadas por videoconferência;

- Atividades realizadas no Ambiente Virtual de Ensino-Aprendizagem (AVEA), por meio do Moodle;

- Encontros freqüentes entre gestores (tutores, coordenadores ou professores) sustentados no modelo do software SKYPE;

- Mensagens e troca constante de documentos eletrônicos por email;

- Contatos e providências emergenciais realizados através do telefone.

O caso apresentado retrata um modelo de curso baseado em rede com escolha de mídias, cuja primeira turma colou grau em novembro de 2009. Alguns índices que depõem favoravelmente ao modelo de curso implantado são: baixo índice de evasão (10\%); baixa repetência (24\%); satisfação acadêmica pela qualidade do curso; 
perspectiva positiva de efetiva qualificação e profissionalização na área de Gestão Pública, com contribuição para o desenvolvimento econômico regional.

\section{CONCLUSÕES}

O surgimento da Internet trouxe mudanças ao cenário da educação, juntamente com o aumento da competitividade e globalização, gerando necessidade de uma aprendizagem que se estenda para além do âmbito do convencional territorizado. Essa mudança de concepção dos conhecimentos leva as instituições a repensar os seus papéis, buscando uma educação personalizada, adaptativa e interativa. Os modelos educacionais devem estar aptos a proporcionar o desenvolvimento pessoal, assegurando a qualidade, respeitando o perfil da população alvo, disponibilizando aos estudantes todo o potencial que as mídias podem oferecer.

Em relação ao estudo de caso apresentado, percebe-se que, apesar do sucesso do curso, em função da projeção de crescimento da oferta na modalidade a distância, destacam-se esforços especiais para que se mantenham os índices de conclusão. Entre estes esforços estão melhorias: no AVEA; no desenvolvimento e produção de material didático; nas ferramentas de apoio e acompanhamento; na elaboração e aplicação de provas; no tempo de resposta ao aluno; na comunicação e entrosamento profissional entre tutores presencias e a distância.

Assim, as mídias devem ser cuidadosamente analisadas e selecionadas, devido ao papel fundamental que exercem no processo de comunicação no curso e também devido à sua influencia na motivação do estudante, já que seu uso inadequado seguramente é um dos fatores que acarretam desmotivação, baixa qualidade do curso e alto índice de evasão. Os programas e cursos de EaD devem ser planejados, implementados e conduzidos com base numa política que privilegie as suas especificidades, adotando boas estratégias de organização, de disponibilização de conteúdo e de interação entre estudantes, professores e tutores, de forma a atender fundamentalmente as necessidades do estudante e a proporcionar condições adequadas de ensino-aprendizagem.

Cabem aqui as palavras de Ribas e Hermenegildo (2008, p. 10),

O uso consciente das tecnologias questiona os papéis da instituição, do professor e do aluno. Não reside, pois, na modalidade - a distância ou presencial - e sim na transição de uma educação estritamente institucionalizada para uma situação de troca midiatizada. Isso implica dizer que, em $\mathrm{EaD}$, o processo de ensino e aprendizagem transforma-se, passando de uma entidade institucionalizada para uma entidade aberta e coletiva.

\section{REFERÊNCIAS BIBLIOGRÁFICAS}

ALMEIDA, M. E. B. Educação a Distância na Internet: abordagens e contribuições dos ambientes digitais de aprendizagem. Educação e Pesquisa. São Paulo, v.29, n. 2, p. 327340, jul/dez. 2003.

CATAPAN. Araci Hack. Mediação pedagógica diferenciada. In: ALONSO, Katia M.; RODRIGUES, Rosangela S.; BARBOSA, Joaquim G. Educação a distância: práticas , reflexões e cenário plurais. Cuiabá: Ed. UFMT, 2010.

COMARELLA, Rafaela Lunardi. Educação superior a distância: evasão discente. 2009. 147 p. Dissertação (Mestrado) - Programa de Pós-Graduação em Engenharia e Gestão do Conhecimento, Universidade Federal de Santa Catarina, Florianópolis, 2009. 
FREIXO, M. J. V. Teorias e modelos de comunicação. Lisboa: Instituto Piaget, 2006.

KEEGAN, D. The impact of new technologies on distance learning students. E-learning \& education, v. 4, July 2008. Disponível em : http://eleed.campussource.de/archive/4/1422/

KENSKI, V. M. Gestão e uso das mídias em projetos de educação a distância. ECurriculum, São Paulo, v. 1, n. 1, dez. 2005. Disponível em: <http://www.pucsp.br/ecurriculum/artigos_v_1_n_1_dez_2005/vanikenskiartigo.pdf>. MOORE, M. G; KEARSLEY, G. Educação a distância: uma visão integrada. São Paulo: Thomson Learning, 2007.

PETERS, O. A EaD em transição. São Leopoldo: Unisinos, 2002.

PUIG, J. Teoria de la educación, una aproximación sistémico-cibernética. Barcelona: PPU, 1986.

RIBAS, J. C. C; HERMENEGILDO, J. L. S. A Implantação da educação a distância, pelo sistema Universidade Aberta do Brasil, no CEFET-SC: Caminhos e Percursos. Anais do $14^{\circ}$ Congresso Internacional ABED de Educação a Distância: Mapeando o Impacto da EAD na Cultura do Ensino-Aprendizagem. Santos: ABED, 2008

RODRIGUES, R. S. Modelo de planejamento para cursos de pós-graduação a distância em cooperação universidade-empresa. 2004. 176 f. Tese (Doutorado em Engenharia de Produção) - Departamento de Engenharia de Produção e Sistemas, Universidade Federal de Santa Catarina, Florianópolis, 2004.

RUMBLE, G. A gestão dos sistemas de ensino a distância. Brasília: UNB/UNESCO, 2003.

SANCHEZ, F. Anuário brasileiro estatístico de educação aberta e a distância, 2007. São Paulo: Instituto Monitor, 2007.

THAYER, L. Comunicação: fundamentos e sistemas. São Paulo: Atlas, 1979. 